Commentary on Autobiographical Memory Narratives in Psychotherapy: A Coding System Applied to the Case of Cynthia

\title{
Developing a Systematic Procedure for the Assessment of Self-Defining Memories in Psychodynamic Therapy: Promise and Pitfalls
}

\author{
KATHRIN MOERTL ${ }^{\mathrm{a}, \mathrm{c}}$, TALI Z. BORITZ ${ }^{\mathrm{a}}$, \\ EMILY BRYNTWICK ${ }^{\text {a }}$, \& LYNNE ANGUS ${ }^{a}$ \\ ${ }^{\mathrm{a}}$ Department of Psychology, York University, Toronto, Canada \\ ${ }^{\mathrm{b}}$ Correspondence concerning this article should be addressed to Kathrin Moertl, Department of Psychology, York \\ University, Room 248 BSB, 4700 Keele Street, Toronto, ON, Canada, M3J 1P3 \\ Email: moertl@yorku.ca
}

\begin{abstract}
The innovative approach to assessing autobiographical memory narratives that Singer and Bonalume (2010) demonstrate in their case study of Cynthia is an ambitious expression of integrative psychotherapy research. It brings together the rich research findings on self-defining memories derived from laboratory studies and therapy case analyses, and applies these to the multimodal assessment situation in a psychotherapy program. Further, Singer and Bonalume's case of Cynthia is grounded in a truly "common factor" that is essential to most if not all psychotherapies: patient narrative expression. However, the integration of findings across different research studies still needs further elaboration to clarify and explore when they are consistent and when they are inconsistent with one another. In our commentary we critically assess the following issues associated with Singer and Bonalume's narrative memory coding system and its application to the case of Cynthia: (a) the utilization of narrative analyses for the identification of themes; (b) challenges inherent in establishing criteria for the identification of clinically important autobiographical memory narratives in therapy sessions; (c) the degree of integrative processing that takes place in narrative expression; and (d) the process of formulating inferences based on client narrative expression in assessment interviews versus therapy sessions. The commentary concludes with a discussion of promising future directions for narrative research in psychotherapy.
\end{abstract}

Keywords: psychodynamic psychotherapy; psychoanalysis; predictors in psychotherapy; prediction and narratives; memory narratives; memory and psychotherapy; case study; clinical case study

\section{OVERVIEW}

Psychotherapy started as a "talking cure" over a hundred years ago and has since developed its various techniques on how to conceptualize and work with what is being presented in the therapeutic setting, including both the verbal and non-verbal. However, the spoken word is 
Memories in Psychodynamic Therapy: Promise and Pitfalls

K. Moertl, T.Z. Boritz, E. Bryntwick, \& L. Angus

Pragmatic Case Studies in Psychotherapy, http://pcsp.libraries.rutgers.edu

Volume 6, Module 3, Article 3, pp. 203-214, 11-09-10 [copyright by authors]

still focal in all psychotherapies and, hence, psychotherapy process research. Words form the narratives presented in the stories that clients tell, as well as the verbal interactions between therapist and patient. In their case study of Cynthia, Singer and Bonalume (2010) draw upon these commonalities when investigating autobiographical memory narratives in psychodynamic psychotherapy.Narrated autobiographical memories (ABMs), however, have a different function in different therapeutic approaches. For example, ABMs have traditionally been more pivotal in the humanistic and psychodynamic traditions. ${ }^{1}$ In Singer and Bonalume's case of Cynthia, the authors refer to a psychodynamic rationale, investigating central themes and conflicts, defenses, and transferential patterns. Their Coding System for Autobiographical Memory Narratives in Psychotherapy (CS-AMNP; Singer \& Bonalume, 2008) represents a sophisticated instrument for the analysis of narrative structure and content. The strength of the single case study is that the authors outline examples and link them to other research findings and theoretical concepts, which makes this conclusion traceable and highly comprehensible for clinicians.

\section{THEMES AND PLOTLINES IN AUTOBIOGRAPHICAL MEMORIES (ABMs)}

At the onset, it is important to note that Singer and Bonalume's case study of Cynthia is part of a larger body of research work in the area of ABMs and psychotherapy. Below we discuss this context, hoping to motivate further collaboration among research groups in this area.

By looking at the predominant themes present in Cynthia's ABMs, we learn that Cynthia's few specific ABMs are all embedded in an "agentic theme”: every time she experiences a streak of independence or sense of autonomy, this notion, so the authors suggest, is either rejected by others or sabotaged by herself. The narrative presentation of the ABMs suggest that Cynthia is motivated to engage in reflection about this theme and question her reactions. This finding is highly interesting as it pinpoints a generic core conflict that can serve a diagnostic purpose and be used in treatment planning.

The categorization of core themes in Cynthia's single case study can be compared to the diagnostic procedure in the manual of the Operationalized Psychodynamic Diagnostics system (OPD-2; OPD Task Force, 2007). Therein, the OPD trained psychotherapist conducts assessment interviews and, among other tasks, formulates a predominant conflictual theme (axis III in the OPD) for the patient. The conflictual theme is chosen from seven theoretically derived categories (e.g., need for care vs. self-sufficiency conflict) that are described in the OPD manual. Unlike this top-down approach of axis III in OPD, in Cynthia's case study Singer and Bonalume use a

${ }^{1}$ In cognitive-behavioral therapies the conceptualization of ABMs might be limited to the gathering of information in order to understand maladaptive schemas, thoughts, behaviors, and emotions. In constructivist cognitive approaches, ABMs have an additional experiential characteristic that serves the function of de- and re-construction of self-experiences (Goncalves, Henriques, \& Machado, 2004, pp. 104). In experiential, emotion-focused therapy, the disclosure of specific ABMs is highly important, since in such disclosures the client can begin to make meaning of repetitively experienced maladaptive emotions (Boritz et al., 2010). In psychodynamic therapies, actualized neurotic transference patterns in ABMs are worked through as they are repeatedly recalled, reconstructed and re-experienced (Book, 2004 pp 77). 
Memories in Psychodynamic Therapy: Promise and Pitfalls

K. Moertl, T.Z. Boritz, E. Bryntwick, \& L. Angus

Pragmatic Case Studies in Psychotherapy, http://pcsp.libraries.rutgers.edu

Volume 6, Module 3, Article 3, pp. 203-214, 11-09-10 [copyright by authors]

bottom-up strategy, deriving the core theme from Cynthia's individual experience, providing a tailor-made and highly precise categorization. The OPD also offers another axis that can be compared to the affective scripts in Cynthia's case study. In axis II of the OPD, the psychotherapist summarizes the maladaptive interpersonal patterns that were present in the assessment interview.

The development of this part of the OPD and OPD-2 manual can be traced back to the broad research basis of Benjamin's (1993) Structural Analysis of Social Behavior and the "Core Conflictual Relationship Themes" (CCRT) movement (Luborsky, 1984), in which the wish of the subject and the resultant reaction of the object are outlined ${ }^{2}$. Comparable to Cynthia's case study, the CCRT method can be applied by creating categories that are inductively derived from an individual case, and thus tailor-made to the case. The OPD also formulates the interpersonal patterns (axis II) inductively, which results in a formulation very similar to the affective scripts presented by Singer and Bonalume.

Finally, one of our ongoing narrative research projects at York University (Levin, Angus, \& Moertl, 2010) will investigate the prevalence of OPD conflictual themes in therapy sessions selected from good and poor outcome clients who participated in the York I Depression Study (Greenberg and Watson, 1998). This content analysis will look at the frequency of conflictual themes within sessions that will then be linked to therapy outcome findings using prepost change scores on the Beck Depression Inventory (Beck et al., 1961). Again, this deductive top-down analysis will not be able to target or evaluate the individual change process of each patient. To do that we will conduct a qualitative analysis of relational plotlines (based on the above-described interpersonal patterns, OPD axis $\mathrm{II}^{3}$ ) that occur within and across sessions of individual clients. This study will focus on the narrated positioning of the self and others over time, making use of a narrative-identity coding scheme introduced by Lucius-Hoene and Deppermann (2002). As cited by Singer and Bonalume, some fundamental work in this area has been published by Demorest (1995, 2007). Just recently Siegel and Demorest (2010) have published a new analysis on affective scripts using the FRAMES ${ }^{4}$ (Fundamental Repetitive and Maladaptive Emotion Structures by Hoelzer \& Dahl, 1996). In this work, they present a

2 The CCRT method has been further developed by multiple research teams. One prominent application of this method is the CCRT-LU, where "LU" stands for "logically unified" and the "Leipzig-Ulm" cooperative project. The CCRT-LU method adds further reciprocal structures between the self and object wishes and reactions, and this method provides an elaborated, standardized category system of harmonious and disharmonious categories (Albani, Pokorny, Glaser \& Kaechele, 2008; also see www.ccrt-lu.org)

${ }^{3}$ This research project is funded by the DFG (German Research Council).

${ }^{4}$ In this case, a very short description of the method is provided, but for a more complete understanding, readers are encouraged to seek out the original article: "Unlike other methods ... [the FRAMES use] standard content categories in order to code narrative events for interpersonal behaviors. The result is a representation of an interpersonal schema with idiographic structure but nomothetic content: a specific sequence of standard categories - a coded sequence - that uniquely identifies a maladaptive pattern. Thus, the pattern can be systematically tracked across psychotherapy” (Siegel \& Demorest, 2010, p. 370). 
Memories in Psychodynamic Therapy: Promise and Pitfalls

K. Moertl, T.Z. Boritz, E. Bryntwick, \& L. Angus

Pragmatic Case Studies in Psychotherapy, http://pcsp.libraries.rutgers.edu

Volume 6, Module 3, Article 3, pp. 203-214, 11-09-10 [copyright by authors]

systematic case study using their highly standardized instrument to track affective scripts. In addition, the "Innovative Moments" group in Portugal is conducting research on the narrative construction of self and others throughout the therapy process (Goncalves, Matos, \& Santos, 2008). Again, by highlighting the diversity of narrative research efforts underway in the psychotherapy research literature, we hope to motivate further collaboration among research groups. It is exciting to us to see different research teams working on related issues, with the possibility of mutual enrichment of each others' work.

\section{A CLOSER LOOK AT DEFINING CLINICAL ABMs}

By carefully comparing and contrasting autobiographical memory research initiatives underway in the field of psychotherapy research, an interesting conceptual difference emerges between Singer and Bonalume's CS-AMNP and the Narrative Process Coding System (NPCS) set forth by Angus et al. (1999). This difference involves the definition of ABM. In the NPCS, autobiographical memory specificity is determined based on an adapted version of Singer and Moffitt’s (1992) scoring manual for autobiographical memory narrative subtypes.

While there is overlap in the scoring of specificity of autobiographical memory, the two systems diverge over the basic definition of autobiographical memory. For Singer and Bonalume, an autobiographical memory is a recollection of a personally experienced or witnessed event that has happened at least 12 months prior to the time of disclosure. While the NPCS similarly defines ABM as a personally experienced past event, it does not set a time frame for these memories. Thus, no distinction is made between ABMs experienced one day versus one year in the past. The NPCS definition allows for the capture of important autobiographical events unfolding in the current life of the individual. This difference in Singer and Bonalume's CS-AMNP coding system and that of the NPCS has a great impact on what is picked up by the coding system. For example, Singer and Bonalume will miss out on recent autobiographical events that provide information about the client's present position and level of distress-e.g., in the case of Cynthia, the substance abuse and self-harm behavior appear to be present in the context of the client's current functioning, although these behaviors are not indicated in the autobiographical memories picked up by the CS-AMNP.

That being said, this divergence may in part be explained in terms of the particular theoretical rationale. For example, in the psychodynamic framework, the specific situation can signify a maladaptive pattern. This is sometimes referred to as "psychoanalytic narrative," which is a theoretical depiction and not an empirically descriptive category. Kaechele and Thomae (2008) state that this expression refers to narrative statements that present specific events as elements in a history (referring to Danto, 1965). Kaechele and Thomae (2008) elaborate:

Since psychoanalytic explanations lie within the totality of a life history, the denotation psychoanalytic narrative - which as far as we know was first used by Farrell (1961) in philosophical discussion — underlines the historical character of psychoanalytic explanations. (p. 84)

If we look at the general theory of neurosis as a fundamental concept of psychodynamic theory, more specifically the neurotic conflict resolution (Mentzos, 1984), every symptom has 
Memories in Psychodynamic Therapy: Promise and Pitfalls

K. Moertl, T.Z. Boritz, E. Bryntwick, \& L. Angus

Pragmatic Case Studies in Psychotherapy, http://pcsp.libraries.rutgers.edu

Volume 6, Module 3, Article 3, pp. 203-214, 11-09-10 [copyright by authors]

symbolic character and stands for a complex creative resolution attempted by the psyche, including defense strategies, structural conditions, external resources, and so forth. We can conclude that looking at specific ABMs in the context of Singer and Bonalume's definition of autobiographical memory stand for broad, maladaptive, psychodynamic patterns. Thus, Singer and Bonalume's empirical analysis dovetails with psychoanalytic tradition, whereas the definition of autobiographical memory used in the NPCS is embedded in humanistic psychological theory.

In emotion-focused therapy (Greenberg, 2004) and interpersonally oriented psychodynamic therapies (e.g., Strupp \& Binder, 1984), practitioners view the disclosures of specific ABMs as essential for accessing and differentiating painful emotions that are the basis for new self-understandings (Anderson, Carson, Keefe, \& Darchuk, 2004) and personal insight (Angus \& Hardtke, 2007). While in both traditions the narrating process is an active change process per se-either referred to as "experiential" or "working-through"—-the specific temporal scope is different. Taking this into consideration, our research projects on the same material might generate different results. The extraction of ABMs for further qualitative or quantitative analysis ${ }^{5}$ would yield a different subsample, which might influence the main results and lead to different conclusions. This specific issue highlights the challenges of integrative psychotherapy research, where, despite very clear similarities of research instruments and analytic techniques, one has to look very closely at operational definitions in coding systems and their theoretical underpinnings in order to produce a valid comparison of results. As long as this is accounted for, triangulation among research groups promises to be the future direction in psychotherapy research in general.

\section{ABMs AND NARRATIVE-EMOTIONAL PROCESSES}

Following the narrative analysis of Cynthia further, Singer and Bonalume report that she articulated few integrated ABMs, specifically, the type of memories in which she demonstrates reflective and meaning-making efforts. It is also reported that Cynthia does not disclose any ABMs that end with a positive emotion or related sense of triumph (a "redemption" story). Meanwhile, there are six "contamination" stories, which are characterized by closing with a feeling of disappointment or frustration.

Besides the vivid impression that this material evokes for clinical considerations, we were struck by the conceptual overlaps to our own work on ABMs, narrative sequences, and story types. In the recently developed "Narrative Emotion Process Coding System" (NEPCS, Boritz, Bryntwick, Angus, \& Greenberg, 2010) we have identified eight categories of storytelling that are prevalent in depressed clients receiving experiential therapy. Two of these story typesthe Unique Outcome Story and the Same Old Story-appear to overlap nicely with the ABMs

\footnotetext{
5 Although the topic of qualitative and quantitative strategies in narrative research would be highly interesting at this point, we will not go into more detail in this commentary. We do want to point out, however, that we are aware that the differentiation between qualitative or quantitative does not do justice to modern and complex research strategies (as outlined and critically discussed by Moertl \& Lamott, 2010). However, the differentiation does provide a good enough explanation in this context, and until our scientific community creates and perpetuates a new common differentiation, we will refer to this rather general one.
} 
Memories in Psychodynamic Therapy: Promise and Pitfalls

K. Moertl, T.Z. Boritz, E. Bryntwick, \& L. Angus

Pragmatic Case Studies in Psychotherapy, http://pcsp.libraries.rutgers.edu

Volume 6, Module 3, Article 3, pp. 203-214, 11-09-10 [copyright by authors]

disclosed by Cynthia. The Unique Outcome Story refers to client narratives involving descriptions of "new" behaviors, emotional responses, and/or thought patterns, and often involves specific autobiographical memories detailing the expression of new, adaptive actions, reactions, and/or emotions in the context of previously troubling events/scenarios. The new outcome is often experienced as positive and might therefore be similar to the redemption story. The Same Old Story on the other hand refers to client narratives that describe over-general descriptions of interpersonal patterns and emotional states, and it is characterized by a sense of stuckness, which might be comparable to the contamination story. To build upon our independent research findings on these two story types, it would be interesting to open up a dialogue with Singer and Bonalume about our respective work, as these story types seem to have important potential in the prediction of successful versus unsuccessful processes in psychotherapy. This leads us to our final remarks on the topic of prediction.

\section{CLINICAL PREDICTIONS BASED ON ABMs}

So far, our comments have been exclusively directed towards the application of the CS-AMNP to Cynthia's assessment interview, and have not addressed the second important part of Singer and Bonalume's study: prediction to psychotherapy process based on the ABM analysis. The idea of basing such predictions on grounded, earlier-collected empirical ABM material of an intense case analysis is highly innovative. Current predictor research in psychotherapy (for a compiled overview see a Special Issue in Psychotherapy Research, introduced by Barber, 2007) is usually carried out by choosing specific variables that mediate good outcome. Prominent variables identified are specific aspects of the therapeutic alliance and interpersonal behavior, as measured by questionnaires such as the Inventory of Interpersonal Problems (Horowitz, 1999). Additionally, in psychodynamic predictor research, emphasis has been placed on attachment variables and the utilization of complex statistical analyses to investigate the contributions of client individual differences variables for treatment outcomes. On the one hand, there is rich potential for new understandings illustrated in case-based analysis like Singer and Bonalume's withinthe context of this variable-based emphasis in predictive research. On the other hand, we believe that there has been a critical gap in contemporary predictor research that might be closed by case-based narrative research. Specifically, there is no explicit single-case research tradition, no tradition of predicting psychotherapy process derived from the information gathered in a bottom-up single case study. It would be highly interesting to look at specific variables (e.g., specificity of ABM, integration within ABM, dominant themes, and maladaptive plotlines) that mediate therapy outcome.

Singer and Bonalume introduce the predictor section of their study by stating that its purpose is "to explore the utility of the memory coding system for case formulation, treatment planning, and impact upon the actual conduct of therapy" (2010, p. 150), and they later acknowledge that "of course the prediction exercise we employed as one approach to validating the system is quite methodologically limited" (p. 154). In this context, we would like to expand upon the methodological limitations with this type of exercise. Specifically, we were left wondering if specific variables at play in therapy relationships can be predicted on the basis of autobiographical memories disclosed in assessment interviews. Narratives produced in an assessment interview are shaped by specific contextual factors inherent in that setting. Furthermore, some predictive questions were based on the current transferential patterns to the 
Developing a Systematic Procedure for the Assessment of Self-Defining

Memories in Psychodynamic Therapy: Promise and Pitfalls

K. Moertl, T.Z. Boritz, E. Bryntwick, \& L. Angus

Pragmatic Case Studies in Psychotherapy, http://pcsp.libraries.rutgers.edu

Volume 6, Module 3, Article 3, pp. 203-214, 11-09-10 [copyright by authors]

assessment interviewer, aiming to forecast future transferential patterns unfolding in therapy sessions with a different therapist. Also, assessing the quality of future dynamics, defenses, and quality of relationship to another therapist, based on very early information, might lead to predetermined ways of seeing and experiencing the patient that could lead to interpersonal misunderstandings and relational ruptures in psychodynamic therapies. Even when the information collection was well thought through, by choosing an independent diagnostician and choosing an interview technique that motivated the client to narrate, the assessment material poses limitations for valid predictions.

We know from Buchheim, Cierpka, and Seifert (1998) that narrating comes in different forms, depending on the therapeutic framework. Referring to their introductory words in an anthology of the Lindauer Psychotherapy Weeks on “The Narrative” in 1998, therapists in different settings do invite patient narrations in distinguishable ways. While this is true for different psychotherapy approaches (Buchheim et al., 1998, p. v), it is also true for clinical and research settings: structured assessment interviews will produce different narratives than the psychotherapeutic process. The assessment situation can produce very rich narratives, as the client is asked to summarize major problems and concerns in a limited time frame.

The bio-psycho-social interview is not designed to extract singularly problematic narratives, but to stay opened and motivate the client to freely narrate. Still, the first encounter between patient and therapist and the question of what brings the patient to therapy does evoke a specific kind of focus, namely the problematic topics. In the single-case analysis presented by Singer and Bonalume, this forms a major limitation. The authors find that Cynthia did not produce any redemption stories with a positive outcome. However, it is possible that this is an artefact of the assessment setting rather than information about the client herself. An assessment interview is usually shaped around the more problematic issues, and often does not take into account what is going well for the client - even if this information is prompted for by the interviewer.. This calls into question the comparison of Cynthia's high amount of generic narratives at $45.8 \%$ to the usually lower amount of about $15-20 \%$ typically collected in the laboratory research. Either the comparison must be made to other assessment-based results of generic memories, or if one dismisses the comparison to an external normative group the comparison of early and late frequencies within the same individual might be focused. However, this would necessitate an analysis across therapy sessions or across pre-post interviews within the same client.

Additionally, the independence of the diagnostician and therapist has its advantages, but also brings with it a major limitation. The assessment situation will yield specific narratives, also directed to this specific interviewer in this specific transference situation. One might of course argue that the core transferential patterns and conflicts, according to psychodynamic therapies, are relatively stable (Thomae \& Houben, 1967, p. 678), and similar transferential processes will evolve towards the one therapist as well as towards another therapist. But our own argument is not from a theoretical perspective of transference development. The initial contact situation between a therapist or diagnostician and a patient either invites or inhibits the patient to tell certain stories in this initial time frame. Therapist factors, e.g. the sex, age, or ethnicity of the therapist or diagnostician influence what the patient is willing to tell, especially in the first sessions. In a related way, the therapeutic alliance that forms in the actual therapy might have a 
Developing a Systematic Procedure for the Assessment of Self-Defining

Memories in Psychodynamic Therapy: Promise and Pitfalls

K. Moertl, T.Z. Boritz, E. Bryntwick, \& L. Angus

Pragmatic Case Studies in Psychotherapy, http://pcsp.libraries.rutgers.edu

Volume 6, Module 3, Article 3, pp. 203-214, 11-09-10 [copyright by authors]

completely different quality compared to the alliance formed in the assessment, simply because the therapist is a different person; and this might be independent of the patient characteristics or the information gathered from the narratives. For example, highly painful or shame-related topics might not be addressed in the assessment, because a safe therapeutic environment and relationship has not yet been established. For example, considering the case of Cynthia, it is possible to imagine that her substance abuse and self harm were such topics and thus not disclosed at the point of the assessment. Thus, the question emerges: how can we adjust a predictor analysis, knowing about these specific limitations? We believe that basing predictions solely on the ABMs disclosed in the assessment interview might not allow a prediction of the therapeutic relationship and transference, and also might not provide enough information to address aspects according to emotion regulation and coping strategies. That said, the analysis of ABMs in these assessment interviews is valuable and informative for the purposes of training and supervision - a stated aim of Singer and Bonalume - guiding novice therapists to formulate a diagnosis or treatment plan.

This last remark may seem to contradict what we said earlier: If the information gathered from early assessment ABMs has clinical relevance for treatment planning, then why should it not be used for making predictions about the client and the therapeutic process? We want to underline that predictions are part of all psychotherapy across the different stages of therapy. As Hartmann (1958) outlined for psychodynamic therapies: "prediction, or predictability, is in the analysis not accidental but belongs to its essence. And it is obviously true ... that our technique is constantly based on such tentative predictions" (p. 121). However, in terms of the predictions formulated in Singer and Bonalume's work, there is one major limitation that calls into question the utility of such predictions: clinical predictions are usually made short-term. Kaechele and Thomae (2008) extensively discuss predictability in their book, From Psychoanalytic Narrative to Empirical Single Case Research: Implications for Psychoanalytic Practice (2008, pp 36), stating that one must differentiate between prediction (or prognosis: a priori, directed towards a later point in time), and analysis (or explanation: a posteriori, providing an explanation for past events/behaviors). For the field of predictions, it must be considered that every line of progress beholds different possibilities, because of alternative border conditions to each development. Kaechele and Thomae (2008) summarize:

Freud himself explains the pessimistic result — that synthesis (or prognosis) is impossible with the lack of knowledge about further causes. These causes are, however, nothing other than border conditions, which can, of course, looking back at the pathogenesis, never be known. (p.89) [Moreover,] the greater the number of border conditions the more degrees of freedom exist and the factors of uncertainty in the prediction increase proportionately" (p. 93).

Current conceptualizations of factors of change (Kaechele \& Strauss, 2002; Lambert \& Barley, 2002; Wampold, 2001; Lambert \& Ogles, 2004) show that approximately $40 \%$ of all factors of change can be accounted for by causes outside the therapy itself, such as the patient's life circumstances. Looking at the exact prediction in Singer and Bonalume's (2010) article, their sometimes vague formulations seem to be a product of these degrees of freedom: "I would guess she attended roughly 30 sessions," or, "I think she might have had a tendency to come a little bit late" (Table 3, Questions 3 and 4, respectively, p. 163). Relating to the question about 
Memories in Psychodynamic Therapy: Promise and Pitfalls

K. Moertl, T.Z. Boritz, E. Bryntwick, \& L. Angus

Pragmatic Case Studies in Psychotherapy, http://pcsp.libraries.rutgers.edu

Volume 6, Module 3, Article 3, pp. 203-214, 11-09-10 [copyright by authors]

therapeutic relationship, Singer and Bonalume outline two possible directions in which the relationship and transferential patterns might develop: "If the therapist was a positive maternal figure ... she would truly bond ... [if not] then she would be too defended ... and the alliance would be rather vague and abstract."

These predictions cannot be criticized for the rather vague content because in remaining so they take account of the above-described alternative progress lines the patient might take. Still, by predicting two possible outcomes, or sometimes vaguely suggesting one outcome (as in predicting attendance at the therapy sessions), the image is drawn that the client already brings all the criteria into the assessment and the analyst can, judging from the first assessment sessions, predict one (or at least two) possible directions. This would mean psychodynamic therapies conceptualize the patient's behavior and intrapsychic patterns as predetermined. Given the engagement of both authors in psychodynamic research and practice it might be informative to have this particular assumption clarified in their response to this commentary.

Despite our argument that this kind of prediction is problematic, we would like to highlight a more feasible way of prediction, although one that is not altogether new. Both Waelder (1963) and Anna Freud (1958), as outlined by Kaechele and Thomae (2008p. 93), suggested that there are ways of prediction in psychoanalysis if the degrees of freedom of border conditions are limited. As psychodynamic constellations are related, there is valid presupposition as to which direction a development might take. However, with as the alternatives increase, or the longer the time period between the current situation and the predicted situation, the less probable the prediction. If predictions are formulated short-term, for example, to be used for the next immediate step in treatment (see Kaechele \& Thomae, 2008, p. 94), then prognostic statements will be reasonable ${ }^{6}$.

\section{FUTURE DIRECTIONS FOR NARRATIVE RESEARCH IN PSYCHOTHERAPY}

We hope we have highlighted how innovative and important the research is that Singer and Bonalume have presented in their case study of Cynthia. The application of their coding system to assessment and/or psychotherapy sessions has shown how distinctive and richly productive it can be to investigate patients' narratives. We think that the case study of Cynthia is highly informative to clinicians, and has a good deal of potential value for supervision and training purposes. However, in terms of predicting psychotherapy process and outcome based on narratives, we argue that predictions based on ABMs disclosed during assessment interview should only be made for the short-term.

\footnotetext{
6 In this context, we want to mention the Control-Mastery Theory (formulated by Weiss in the 1960s, Weiss, 1993), in which we find a vivid conceptual outline for various courses a psychotherapy can take depending on how the therapist reacts to specific "tests" (referred to as constant transference tests) in the therapeutic relationship (Rappoport, 2002). This would also speak against long term predictions, but support the necessity of short-term predictions, based on narrative content. Recent studies triangulating the Control-Mastery Theory with other therapeutic process models (e.g. the ongoing project by Gandini, 2010) are promising.
} 
Memories in Psychodynamic Therapy: Promise and Pitfalls

K. Moertl, T.Z. Boritz, E. Bryntwick, \& L. Angus

Pragmatic Case Studies in Psychotherapy, http://pcsp.libraries.rutgers.edu

Volume 6, Module 3, Article 3, pp. 203-214, 11-09-10 [copyright by authors]

With respect to statistically-based predictor research, ABMs could be investigated for their mediating role in therapeutic outcome. For example, Singer and Bonalume's CS-AMNP coding system, if applied systematically to a larger sample, could well spearhead a promising new approach in this area. Singer and Bonalume mention that Cynthia is the first case study to be drawn from a sample consisting of 30 patients, and thus we look forward to future findings extending from this sample. We also hope that this is the beginning of more dialogue and collaboration among the various international, narrative research laboratories.

\section{REFERENCES}

Albani, C., Pokorny, D., Glaser, G., \& Kaechele, H. (2008). Beziehungsmuster und Beziehungskonflikte (Relationship patterns and relationship conflicts). Göttingen: Vandenhoeck \& Ruprecht.

Anderson, T., Carson, K. L., Keefe, F., \& Darchuk, A. C. (2004). The influence of social skills on private and interpersonal emotional disclosure of negative experiences. Journal of Social and Clinical Psychology, 23, 635-652.

Angus, L., \& Hardtke, K. (2007). Margaret's story: An intensive case analysis of insight and narrative process change in client-centered psychotherapy. In L. G. Castonguay \& C. Hill (Eds.), Insight in psychotherapy, pp. 187-205. Washington, DC: American Psychological Association.

Angus, L., Levitt, H., \& Hardtke, K. (1999). The Narrative Process Coding System: Research applications and implications for psychotherapy practice. Journal of Clinical Psychology 55, 1255-1270.

Barber, J. (2007). Issues and findings in investigating predictors of psychotherapy outcome: Introduction to the special section. Psychotherapy Research, 17, 131-136

Beck, A. T.,Ward, C. H., Mendelson, M., Mock, J., \& Erbaugh, J. (1961). An inventory for measuring depression. Archives of General Psychiatry, 4, 561-571.

Benjamin, L.S. (1993). Interpersonal diagnosis and treatment of personality disorders. New York: Guilford Press.

Book, H. (2004). The CCRT approach to working with patient narratives in psychodynamic psychotherapies. In L. Angus \& J. McLeod (Eds.). The handbook of narrative and psychotherapy, pp 71-87. Thousand Oaks, CA: Sage.

Boritz, T., Angus, L., Monette, G., Hollis-Walker, L., Warwar, S. (2010). Narrative and emotion integration in psychotherapy: Investigating the relationship between autobiographical memory specificity and expressed emotional arousal in brief emotion-focused and clientcentered treatments of depression. Psychotherapy Research: Ifirst, 1-11. (New electronic article ahead of the print edition, posted 9-8-10, accessible at: http://pdfserve.informaworld.com/313414_762317394_926722796.pdf)

Boritz, T., Bryntwick, E., Angus, L., Greenberg, L. (2010) The Narrative Emotion Process Coding System (NEPCS). Unpublished Coding Manual. Toronto: York University.

Buchheim, P., Cierpka, M., \& Seifert, T. (1998) (Eds.). Lindauer Texte: Texte zur psychotherapeutischen Fort- und Weiterbildung (Lindauer Texts: Texts for psychotherapy advanced education). Berlin: Springer.

Danto, A. (1965) Analytical philosophy of history. Cambridge: Cambridge University Press. 
Developing a Systematic Procedure for the Assessment of Self-Defining

Memories in Psychodynamic Therapy: Promise and Pitfalls

K. Moertl, T.Z. Boritz, E. Bryntwick, \& L. Angus

Pragmatic Case Studies in Psychotherapy, http://pcsp.libraries.rutgers.edu

Volume 6, Module 3, Article 3, pp. 203-214, 11-09-10 [copyright by authors]

Demorest, A. P. (1995). The personal scripts as a unit of analysis for the study of personality. Journal of Personality, 63, 569-591.

Demorest, A. P. (2007). A taxonomy of scnes. Journal of Research in Personality, 42, 239-246.

Farrell, B.A. (1961) Can psychoanalysis be refuted? Inquiry, 4, 16-36.

Freud, A. (1958). Child observation and prediction of development. Psychoanalytic Study of the Child, 13, 92-116.

Gandini, V. (2010, June). Exploring the concept of test of the control mastery theory through the Therapeutic Cycle Model. Presentation at the 41st International Meeting of the Society for Psychotherapy Research. Asilomar, California.

Goncalves, M. M., Matos, M., \& Santos, A. (2008). Innovative moments coding system. Version 7.0. Braga, Portugal: University of Minho. (Available from the authors.)

Goncalves, O., Henriques, M., \& Machado P. (2004). Nurturing nature: Cognitive narrative strategies. In L. Angus \& J. McLeod (Eds.). The handbook of narrative and psychotherapy, pp 103-119. Thousand Oaks: Sage.

Greenberg, L. S. (2004). Emotion-focused therapy. Clinical Psychology and Psychotherapy, 11, 3-16.

Greenberg, L., \& Watson, J. (1998). Experiential therapy of depression: Differential effects of client centered relationship conditions and process experiential interventions. Psychotherapy Research, 8, 210-224.

Hartmann, H. (1958) Diskussionsbeitrag zu A. Freud. Psychoanalytic Study of the Child, 13, 120-122.

Hoelzer, M., \& Dahl, H. (1996). How to find FRAMES. Psychotherapy Research, 6, 177-197.

Horowitz, L. M. (1999). Manual for the Inventory of Interpersonal Problems. San Antonio, TX: The Psychological Corporation.

Kaechele, H., \& Strauss, B. (2008) Brauchen wir Richtlinien oder Leitlinien für psychotherapeutische Behandlungen? (Do we need rules of action or guidelines for psychotherapeutic treatments?). Psychotherapeut, 53, 408-413.

Kaechele, H., Schachter, J., \& Thomae, H. (Eds.). (2008). From psychoanalytic narrative to empirical single case research: Implications for psychoanalytic practice. New York: The Analytic Press.

Lambert, M., \& Barley, D. (2002). Research summary on the therapeutic relationship and psychotherapy outcome. In J. Norcross (Ed.). Psychotherapy relationships that work, pp. 17-32. Oxford University Press, Oxford.

Lambert, M., \& Ogles, B. (2004). The efficacy and effectiveness of psychotherapy. In M. Lambert (Ed.). Bergin and Garfield's handbook of psychotherapy and behavior change, 5th edn, pp. 139-193. New York: Wiley.

Levin, M., Angus, L., \& Moertl, K. (2010). Conflictual themes in emotion-focused treatment for depression. Unpublished Coding System, York University, Department for Psychology.

Luborsky, L. (1984). Principles of psychoanalytic psychotherapy: A manual for supportiveexpressive treatment. New York: Basic Books.

Lucius-Hoene, G., \& Deppermann, A. (2002). Rekonstruktion narrativer Identität. Ein Arbeitsbuch zur Analyse narrativer Interviews (Reconstruction of narrative identity. A textbook to analyze narrative interviews). Wiesbaden: Verlag fuer Sozialwissenschaften.

Mentzos, S. (1984) Neurotische Konfliktverarbeitung. (Neurotic Conflict Resolution). Frankfurt: Fischer. 
Moertl, K., \& Lamott, F. (in press). Wie wird Veränderung in der Psychotherapieforschung gemessen? Ein Plädoyer für triangulierende Forschung (How is change measured in psychotherapy research? A call for triangulation in research). Psychotherapie \& Sozialwissenschaft.

OPD Task Force (2007). Operationalized Psychodynamic Diagnosis OPD-2: Manual of diagnosis and treatment planning. Bern: Hogrefe \& Huber Publishing.

Rappoport, A. (2002). How psychotherapy works: The concepts of control-mastery theory. Bulletin of the American Academy of Clinical Psychology, 8, 10-14.

Siegel, P., \& Demorest A. (2010). Affective scripts: A systematic case study of change in psychotherapy. Psychotherapy Research, 20, 369-387.

Singer, J. A., \& Bonalume, L. (2008). The Coding System for Autobiographical Memory Narratives in Psychotherapy. Unpublished manuscript. New London, CT: Department of Psychology, Connecticut College.

Singer, J.A. \& Bonalume, L. (2010). Autobiographical memory narratives in psychotherapy: A coding system applied to the case of Cynthia. Pragmatic Case Studies in Psychotherapy, Vol. 6(3), Article 1, 134-188. Available: http://hdl.rutgers.edu/1782.1/pcsp_journal

Singer, J. A., \& Moffitt, K. H. (1992). An experimental investigation of specificity and generality in memory narratives. Imagination, Cognition, and Personality, 11, 233-257.

Strupp, H. H., \& Binder, J. L. (1984). Psychotherapy in a new key: A guide to time-limited dynamic psychotherapy. New York: Basic Books.

Thomae, H., \& Houben, A. (1967). Über die Validierung psychoanalytischer Theorien durch die Untersuchung von Deutungsaktionen (On the validation of psychoanalytic theories by the investigation of interpretative actions). Psyche - Zeitschrift für Psychoanalyse, 21, 664-692.

Waelder, R. (1962). Psychoanalysis, scientific method and philosophy. Journal of the American Psychoanalytic Association, 10, 617-637.

Wampold, B. (2001). The great psychotherapy debate. Models, methods and findings. Mahwah, NJ: Erlbaum.

Weiss, J. (1993). How psychotherapy works: process and technique. New York: Guilford Press. 